\section{Consent requirements for pelvic examinations}

I write on behalf of the College of Physicians and Surgeons of Ontario, in response to the recent article in $C M A J$ "Consent requirements for pelvic examinations performed for training purposes." We appreciate that the authors of this article were commenting only on new policy guidelines from the Society of Obstetricians and Gynaecologists of Canada (SOGC), and the Association of Professors of Obstetrics and Gynaecology of Canada (APOG), and the "flaw" in that policy related to medical residents.

Gibson and Downie ${ }^{1}$ note that the new policy fails to require residents to obtain consent prior to conducting pelvic examinations for educational purposes. Although the policy does not specifically address resident responsibilities in this area, this college's policy - Professional Responsibilities in Postgraduate Medical Education ${ }^{2}-$ explicitly addresses the issue. Our mandate is to regulate physicians in the public interest, and our policy clearly states that patients must be given an explanation about the educational purpose of any proposed examination or clinical demonstration and that express consent of the patient must be obtained (whether the patient is conscious during the examination). The policy also clearly states that if, for any reason, express consent cannot be obtained, the examination cannot be performed. Unfortunately, Gibson and Downie ${ }^{1}$ leave the impression that the guideline of the SOGC and APOG is the only policy relevant to this issue. That patients are assured that in Ontario, and probably in most other provinces, this is not the prevailing policy is critical.

Although societies and associations should and do have policies that guide member behaviour, regulatory colleges have the authority to hold physicians accountable in a way those organizations do not.

\section{Robert Byrick MD}

President, College of Physicians and Surgeons of Ontario, Toronto, Ont.

\section{References}

1. Gibson E, Downie J. Consent requirements for pelvic examinations performed for training purposes. CMAJ 2012;184:1159-61

2. The College of Physicians and Surgeons of Ontario. Professional responsibilities in postgraduate medical education. Toronto (ON): The College; 2011.

CMAJ 2012. DOI:10.1503/cmaj.112-2060

The board of the Association of Academic Professionals in Obstetrics and Gynaecology (APOG, formerly the Association of Professors of Obstetrics and Gynaecology of Canada) wishes to respond to the CMAJ article by Gibson and Downie, ${ }^{1}$ which revisits the issue of consent prior to pelvic examination. As the academic organization responsible for support for the academic missions in undergraduate and postgraduate training in obstetrics and gynecology, we have serious concerns.

"Medical trainees" was changed to "medical students" in the revised guidelines, ${ }^{2}$ which identifies the medical student's role in pelvic examination as a learner. The new document is patientfocused and clearly defines informed consent on the part of the medical student and the entire gynecologic surgical team. The document ensures that patients are fully informed about the medical student's role as a learner during clinical care and that patients may opt out of being a participant in the teaching of pelvic examination skills.

Gibson and Downie ${ }^{1}$ expressed concerns about the comprehensiveness of the guideline with regard to the exclusion of residents as medical trainees. Residents are physicians who are qualified medical practitioners and are deemed to have developed their pelvic examination skills to the point where they are able perform them independently — as well as offer supervision to learners. Residents are employed under contract by provincial bodies responsible for residency programs. Under ethical obligations set down by provincial governing bodies, qualified physician residents provide care only with patient consent. Residents certainly continue to learn and acquire experience as do all obstetrician-gynecologists who have already completed their training. The principle of lifelong learning is important for all physicians.

Our Association welcomes input and membership from all interested stakeholders including those from the legal community. We strive to achieve the best possible care for women in the academic environment, while fulfilling our commitment to ensure all health professionals providing care for women are adequately trained. Ideally, this should be carried out in a safe environment for both the learner and the patient without needlessly raising anxiety in the public and putting the clinical academic process in jeopardy. A collaborative approach between legal colleagues and physicians would be much more productive toward achieving this goal.

\section{Margaret L. Morris MD}

President, The Association of Academic Professionals in Obstetrics and Gynaecology, Ottawa, Ont.

\section{References}

1. Gibson E, Downie J. Consent requirements for pelvic examinations performed for training purposes. CMAJ 2012;184:1159-61.

2. Liu KE, Shapiro J, Robertson D, et al. Pelvic examinations by medical students. J Obstet Gynaecol Can 2010;32:873-5. Available: www.sogc.org /guidelines/documents/gui246PS1009E 000.pdf (accessed 2011 Apr. 27).

CMAJ 2012. DOI:10.1503/cmaj.112-2061

\section{The authors respond}

Margaret Morris has missed the point of our article. ${ }^{1,2}$ We agree that some residents conduct pelvic examinations solely for therapeutic purposes (i.e., they are fully trained in conducting 
"As a

\section{CMA company,}

MD has a

\section{national eye}

and is able to look

at what's happening

across the country

and move its software

in that direction."

Dr. Neil Cooper,

Pediatrician, Calgary AB

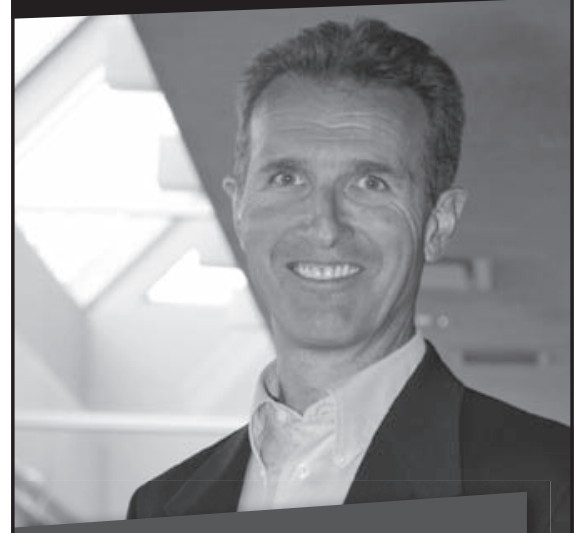

Trust the only EMR solution owned and backed by the CMA.

SEE HOW IT WORKS!

md.cma.ca/EMRcma

Or call 1800 361-9151

1D PHYSICIAN

SERVICES

CMA COMPANIES

\section{Physicians First $^{\text {TM }}$}

PS Suite ${ }^{\circledast}$ Software and related products and services are owned and distributed by MD Practice Software LP, a member of the MD Group.

(8) TM Trademarks of the Canadian Medical Association, used under licence.
LETTERS such examinations and the only purpose for the examination is the care of the patient) and the policy statement does not fail in relation to such residents. However, Morris ignores the fact (explained in our article) that some residents are conducting pelvic examinations solely for training purposes, or for a combination of therapeutic and training purposes. Our considered view, grounded in a careful review of the relevant law, is that patients must be asked for explicit consent to a resident's performing a pelvic examination in whole or in part for training purposes. On this narrow point we took issue with the revisions to the policy statement ${ }^{3}$ because of its shift from covering residents and medical students in this context to only covering medical students. We argued, and continue to hold, that residents should either be added back into the policy statement in relation to the conduct of pelvic examinations for training purposes, or a separate policy for residents (requiring disclosure of purpose and explicit consent for such examinations) should be developed.

We share Morris' goals of achieving "the best possible care for women in the academic environment" and ensuring that "all health professionals providing care for women are adequately trained." However, we do not agree that calling for disclosure of training purposes and explicit consent in residents performing pelvic examinations for training purposes can be characterized as "needlessly raising anxiety in the public and putting the clinical academic process in jeopardy." In a study con- ducted at the Calgary Pelvic Floor Disorders Clinic, a majority of women surveyed indicated that they would consent to a pelvic examination for training purposes if asked. ${ }^{4}$ Further, even if the result would be fewer patients agreeing to have such examinations conducted, this is no justification for overriding legal rights and ignoring ethical responsibilities.

Elaine Gibson LLM, Jocelyn Downie SJD The Health Law Institute, Dalhousie University, Halifax, NS

\section{References}

1. Morris ML. Consent requirements for pelvic examinations [letter]. CMAJ 2012;184:1393.

2. Gibson E, Downie J. Consent requirements for pelvic examinations performed for training purposes. CMAJ 2012;184:1159-61.

3. Liu KE, Shapiro J, Robertson D, et al. Pelvic examinations by medical students. J Obstet Gynaecol Can 2010;32:873-5. Available: www.sogc.org /guidelines /documents/gui246PS1009E 000.pdf (accessed 2011 Apr. 27).

4. Wainberg S, Wrigley H, Fair J, et al. Teaching pelvic examinations under anaesthesia: What do women think? J Obstet Gynaecol Can 2010;32:49-53.

CMAJ 2012. DOI:10.1503/cmaj.112-2052

\section{Letters to the editor}

In submitting a letter, you automatically consent to have it appear online and/or in print. All letters accepted for print will be edited by $C M A J$ for space and style. Most references and multiple authors' names, full affiliations and competing interests will appear online only. (The full version of any letter accepted for print will be posted at cmaj.ca.)

\section{CORRECTION}

\section{"Relevant" not "nonrelevant"}

In the results of the abstract in the research paper by Shariff and colleagues published in the Feb. 21, 2012 issue of $C M A J,{ }^{1}$ the statement, “... while $6 \%$ of the retrieved articles were nonrelevant ...," should have read, "... while $6 \%$ of the retrieved articles were relevant ..." CMAJ apologizes for this error.

\section{Reference}

1. Shariff S, Sontrop JM, Haynes RB, et al. Impact of PubMed search filters on the retrieval of evidence by physicians. CMAJ 2012;184:E184-90.

CMAJ 2012. DOI:10.1503/cmaj.112-2063 